\title{
The Problems with Ultra Long - Term Government Debt (A Case of Ghana Government)
}

\author{
Prof. Emmanuel Opoku Ware
}

\begin{abstract}
The Ghanaian government set a new benchmark for government bond duration. But these long term bonds which have a maturity of 70 years are nearly impossible to price. Moreover, they carry significant interest rate risk and credit risk. Long term financing to infrastructure and mobilization of private long term capital has been recognized as a key agenda in advancing the global economic development. There are several barriers in infrastructure financing and big gaps between expectation and reality. A highly pronounced barrier is the lacking of capacity of investors to price risks in a structured manner. This paper has discussed component-based infrastructure valuation analysis and modeling blocks. The component-based valuation mechanism is very useful for issuers and investors to categorize, analyze and price specific risks transparently and can provide a basis for structuring the risks on an ex-ante basis so as to make project investments suitable for investors of different risk preference.
\end{abstract}

Keywords: Financial Risk, Credit Risk, Concentration Risk Infrastructure Debt Valuation, Credit Asset Pricing, Default Probability, Component Approach.

\section{INTRODUCTION}

This month, with an eye toward locking in a low interest rate for an extremely long period, the Ghanaian government sold $€ 2$ billion of bonds due in November 2086. Undoubtedly, these types of ultra-long bonds present interest rate risk and credit risk challenges.

The duration of the Ghanaian 70-year bond (the weighted measure for the length of time it takes for the payments to become due) has been reported as 43. This extreme value means that if the Austrian interest rate increases from its current (low) level by just one percentage point, the value of the bond for investors would decrease by a hefty $43 \%$.

Interestingly, Ghana's foray into this market is not unprecedented. In 2011, for example, MIT issued a "century bond" (i.e., 100-year duration) for a total notional of $\$ 750$ million. Moreover, on the buyside, pension funds, in particular, seem to have an appetite for such bonds, which they use to match the cash flows of their long-term liabilities.

Yield curves, however, typically break down somewhere between 20 and 30 years. After this term, there's simply insufficient liquidity to valuate the future cash flows properly.

\section{DURATION RISK}

Journalists have noted the high interest rate risk (or duration) of the ultra long-term bond. However, I am not sure whether this is the right way to phrase this risk. In the same way as the laws of classical mechanics crumble if things start moving close to the speed of light, I believe that FRM calculations of duration simply break down when the bond terms are ultra-long.

For a duration calculation, we need the future cash flows as well as a yield curve. Both are used to calculate the present value of the cash flows.

Macaulay duration equals the average time to wait for each payment, weighted by the present values of the cash flows. For modified duration, a small correction is applied to this Macaulay duration. Modified duration can be interpreted as an interest rate sensitivity - or, more precisely, the change in present value after a one percentage point increase of the yield curve.

Following this concept, we can, theoretically, understand why the modified duration is so high (43) for the ultra long-term bond. However, from a practical point of view, the question we must ask is how we calculate that duration. There are no published and reliable yield curves that go on after, say, 
20 to 30 years. At some point in time, the yield curve breaks down - and this point is referred to as last liquid point (LLP).

\section{EIOPA's LAST LIQUID POINT}

Based on its so-called $D L T$ (deep, liquid and transparent) criteria for financial markets, the European Insurance and Occupational Pensions Authority (EIOPA) has investigated what the LLP is for the major currencies.

For interest rate swaps and government bonds, EIOPA has assessed up to what term the market can still be considered liquid. This assessment is based on a number of $D L T$-like operational criteria, such as bid-ask spreads; trade frequency; trade volume; and residual volume (i.e., how much of the government bond volume has a longer term than the LLP).

The outcomes per currency are shown below. The most liquid currencies — dollar and pound sterling - have an LLP of 50 years. The Australian dollar and the Japanese Yen, on the other hand, have an LLP of 30 years, while the euro clocks in at 20 years.

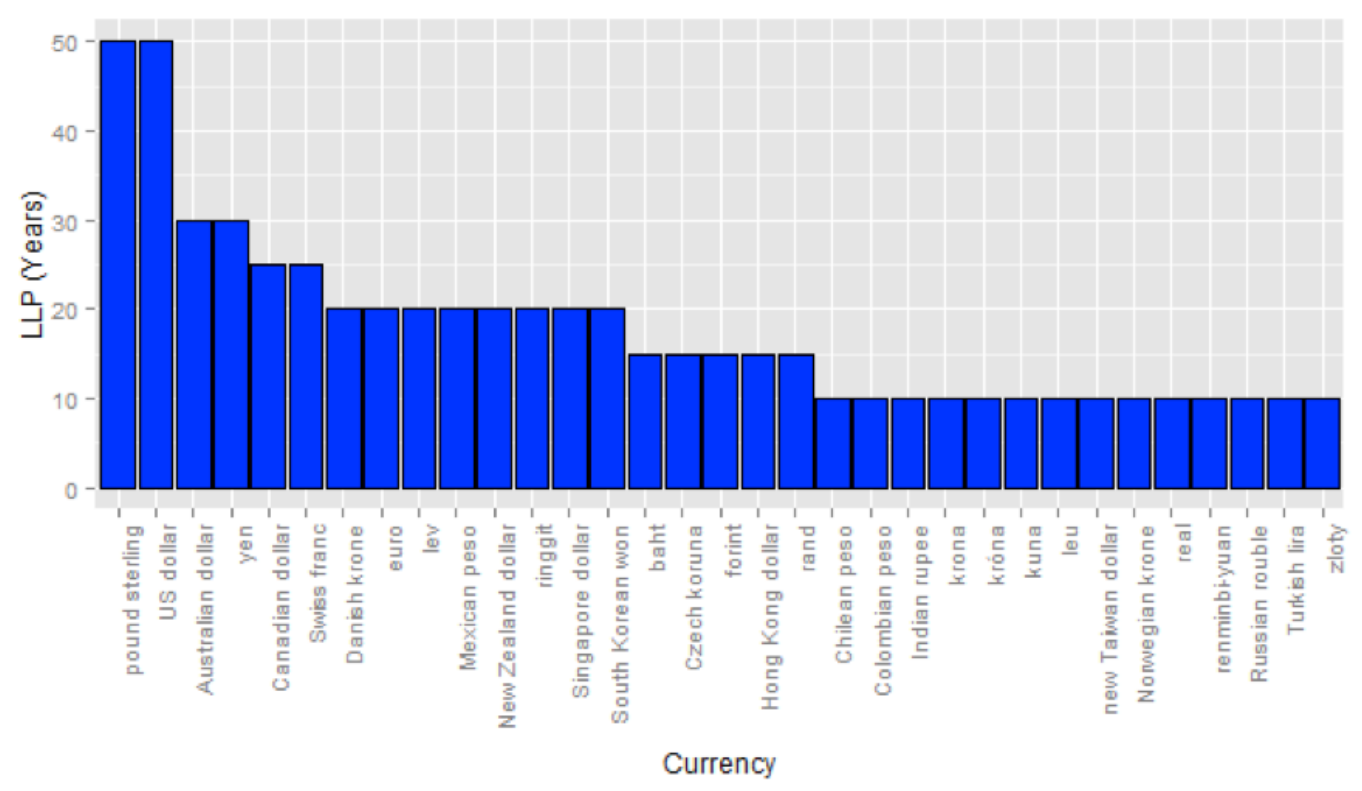

Figure1. EIOPA's Last Liquid Points per Currency

Based on the euro analysis, the 70-year Ghanaian bond term exceeds its applicable LLP by no less than 50 years. Similarly, the MIT century bond exceeds the dollar LLP by a half-century.

\section{CASh Flow and CRedit Risk Dilemmas}

Should we need a discounting curve for maturities after the LLP, extrapolation is needed. We can, of course, apply some assumptions. Broadly speaking, there are two approaches: the yield curve is either just linearly extrapolated after the LLP or extended toward a point implied by an assumed ultimate forward rate.

The drawback of both of these approaches is that the rates established by the extrapolation (the basic linear extrapolation and the more sophisticated UFR extrapolation) are just guesswork. There is simply no clear way to establish the present value of the long-term cash flows.

What's more, there are additional problems. For example, we're very uncertain about the credit risk. How can we be sure, after all, that the Ghanaian government will honor its obligations after 70 years? Indeed, since we can't even be sure that Ghanaian itself will still exist at that time, how can we say with any certainty whether the great-grandchildren of the current Ghanaian treasurers will still be willing and able to pay back the loan?

The same reasoning applies to the century bonds issued by MIT. How can we be sure that this institution will still exist in 100 years? Of course, we hope it does, but counting on that as a fact is neglecting the immensely powerful disruptions (e.g., massive open online courses) that are now challenging the established world of higher education. 
In short, we cannot just assume that interest rates will remain the same after the LLP. Along the same vein, doubts about the creditworthiness of ultra long-term bonds are justified.

When valuation techniques break down, duration cannot be established. Therefore, investing in an ultra-long bond is a gamble akin to investing in a priceless Van Gogh painting — but without the intrinsic value.

Prof. Emmanuel Opoku Ware is a managing director of finance and risk at Opoku\& co. He is also a professor of financial risk management at EPUC University GHANA.

\section{REFERENCES}

[1] BIS (2014). Understanding the Challenges for Infrastructure Finance. Torsten Ehlers Monetary and Economic Department, Working Papers No. 454.

[2] Black, F., \& Cox, J. (1976). Valuing Corporate Securities: Some Effects of Bond Indenture Provisions. The Journal of Finance, 31, 351-367. http://dx.doi.org/10.1111/j.1540-6261.1976. tb01891.x

[3] Black, F., \& Scholes, M. (1973). The Pricing of Options and Corporate Liabilities. Journal of Political Economy, 81, 637-654. http://dx.doi.org/10.1086/260062

[4] Blanc-Brude, F., Hasan, M., \& Ismail, O. R. H. (2014). Unlisted Infrastructure Debt Valuation \& Performance Measurement. French: EDHEC-Risk \& NATIXIS.

[5] Checherita \& Gifford (2007). Risk Sharing in Public-Private Partnerships: General Considerations and an Evaluation of the U.S. Practice in Road Transportation.

[6] Chiara \& Garvin (2007). Valuing Simple Multiple-Exercise Real Options in Infrastructure Projects.

[7] Cuttaree (2008). Successes and Failures of PPP Projects. The World Bank.

[8] Marco \& Blaise (2004/2012). The Term Structure of Credit Spreads in Project Finance. Bank for International Settlements.

[9] Merton, R. C. (1974). On the Pricing of Corporate Debt: The Risk Structure of Interest Rates. The Journal of Finance, 29, 449-470. http://dx.doi.org/10.1111/j.1540-6261.1974.tb03058.x

[10] Mishra, S., Khasnabis, S., \& Dhingra, S. L. (2013). A Simulation Approach for Estimating Value at Risk in Transportation Infrastructure Investment Decisions. Research in Transportation Economics, 38, 128-138. http://dx.doi.org/10.1016/j.retrec.2012.05.009

[11] Moody's (2006). Credit Risk and Loan Evaluation.

[12] Moody's (2012). Infrastructure Default and Recovery Rates, 1983-20-12H1.

[13] Moody's KMV (2010). CDS-Implied EDFTM Credit Measures and Fair-Value Spreads, Modeling Methodologies. Moody's Analytics.

[14] Moody's (2010). Default and Recovery Rates for Project Finance Bank Loans, 1983-2008.

[15] Nobuhide, W. (2006). Business Valuation of Location-Specific Infrastructure Projects in DataPoor Regions.MIT.

[16] Wang, Y. (2009). Structural Credit Risk Modeling: Merton and Beyond. Risk Management.

\section{AUTHOR'S BIOGRAPHY}

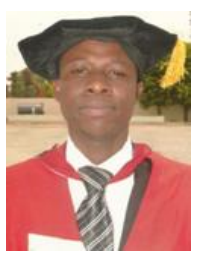

Dr. Emmanuel Opoku Ware, Phd, Cpa, Cia, is Currently the Managing Director / Partner of Opoku Ware \& Co. Financial Engineering Services Consult (Consultants / Practicing Accountants). Senior Partner-J. Allotetey \& Associates (Chartered Accountants) Ghana.

$\mathrm{He}$ is also A Professor and Senior Lecturer of Financial Risk Management, Public Finance/ Economics and Advanced Accounting at West Coast University-USA, E.P. University Ghana and Methodist University College Ghana Respectively.

Fellow of Aafm-USA, Fellow Aia-UK, Certified Public Accountant-USA and UK (Ireland). He is a Researcher and Examiner in Professional Examinations. 